\title{
Amberlite IR-120H: An improved reusable solid phase catalyst for the synthesis of nitriles under solvent free microwave irradiation
}

\author{
Anitha Varghese*, Aatika Nizam, Rajani Kulkarni and Louis George \\ Department of Chemistry, Christ University, Hosur Road, Bangalore, 560029, India \\ ${ }^{*}$ Corresponding author at: Department of Chemistry, Christ University, Hosur Road, Bangalore, 560029, India. \\ Tel.: +91.080.40129313; fax: +91.080.40129000. E-mail address: anitha.varghese@christuniversity.in (A. Varghese).
}

\section{ARTICLE INFORMATION}

Received: 19 December 2011

Received in revised form: 13 March 2012

Accepted: 19 March 2012

Online: 30 June 2012

\section{KEYWORDS}

Nitriles

Araldehydes

Amberlite IR-120H

Microwave irradiation

Solid-phase reusable catalyst

Hydroxyl ammonium chloride

\section{Introduction}

The cyano group is a highly important moiety not only due to its synthetic value as precursor to other functionalities but also due to its presence in a variety of natural products, pharmaceuticals and novel materials [1]. Nitriles are of particular interest in preparative organic chemistry due to their rich chemistry [2-6]. They serve as useful precursors for the synthesis of amines, carboxylic acids, amides, ketones, and heterocyclic compounds, such as tetrazoles [7-9], thiazoles [1011], oxazoles [12-13], 2-oxazolines [14] and 1,2diarylimidazoles [15]. It has also been well documented that the cyano group itself is present in HIV protease inhibitors, 5lipoxygenase inhibitors, and many other bioactive significant molecules [4,5].

Although a plethora of methods are known for access to the cyano functionality [16-19], dehydration of oximes and amides to nitriles is an important transformation in organic syntheses [20-33]. In the last 40 years, a number of efficient methods have been developed for the dehydration of oximes and amides to nitriles [34,35], and the search for better reagents still continues [36]. Also, it is reported that these conversions may be performed either by using bacterial enzymes with aldoximes [37] or by employing oximes ethers under basic conditions [38]. Some recently reported methods for aldoxime dehydration involve sodium dichloroiodate/aq. $\mathrm{NH}_{3}$ [39], $\mathrm{N}$ chlorosuccinimide and pyridine [40], W-Sn mixed hydroxide in $o$-xylene at $149{ }^{\circ} \mathrm{C}$ [41], thermal dehydration [42], reaction with ethyldichlorophosphate/1,8-Diazabicyclo[5.4.0]undec-7ene [43], use of silphos [ $\mathrm{PCl}_{3-\mathrm{n}}\left(\mathrm{SiO}_{2}\right)_{\mathrm{n}}$ ] in $\mathrm{MeCN}$ [44], $\mathrm{ZnO} / \mathrm{AcCl}$ at $80{ }^{\circ} \mathrm{C}$ [45], reaction with chlorosulfonic acid in toluene at 90 ${ }^{\circ} \mathrm{C}$ [46], use of $\mathrm{Ga}(\mathrm{III}) \mathrm{OAc} / \mathrm{MeCN}$ at $85-120{ }^{\circ} \mathrm{C}$ [47], reaction with dimethylacetylene dicarboxylate and $\mathrm{Et}_{3} \mathrm{~N}$ [48], triphenylphosphine $/ \mathrm{CCl}_{4}$ [49] and thionyl chloride in benzotriazole mixture [50]. But most of the reported methods have limitations, such as very corrosive and moisture sensitive reagents [34-38,51-54], use of extremely anhydrous reaction conditions [34-38], cumbersome workup procedures and problems associated with waste disposal [55-57], use of toxic and hazardous chemicals [58-60] and lack of versatility in the transformations conducted in hydrated media [37,38]. To overcome these drawbacks, we attempted to develop a protocol for the conversion of aldehyde to nitrile following Green-Chemistry norms.

The ideology of Green Chemistry calls for the development of new chemical reactivities and reaction conditions that can potentially provide benefits for chemical syntheses in terms of resource and energy efficiency, product selectivity, operational simplicity, and health and environmental safety [61].

As functional group transformations play the most fundamental role in synthesis, synthetic chemists continue to explore new methods which are green to carry out these chemical transformations. One of these green methods is to run reactions using heterogeneous catalyst. As the surfaces have properties that are not duplicated in the solution or gas phase, entirely new chemistry may appear [62]. Even in the absence of new chemistry, a surface reaction may be more desirable than a solution counterpart, because the reaction is more convenient to run, or a high yield of product is attained. For these reasons, synthetic surface organic chemistry is a rapidly growing field of study [62] and the other method is to carry out reactions under solvent-free conditions as this offers a lot of advantages connected to safety, enhancement in reactivity and selectivity, pollution prevention, energy and cost saving. When these conditions are coupled with microwave irradiation, nonthermal effects can be developed, thus allowing considerable improvements over classic procedures [63].

Amberlite IR (Ion exchange Resin) $120-\mathrm{H}$ is a gel type strongly acidic cation exchange resin of the sulfonated polystyrene type. It has excellent physical, chemical and

European Journal of Chemistry 
thermal stability and has emerged as an efficient heterogeneous catalyst for various organic reactions like $\mathrm{N}$ formylation of amines [64], synthesis of various organic compounds like glycosyl dihydro pyridones [65], 1-amidoalkyl2-naphthols [66], 2-aryl-benzimidazoles [67], and glycosyl enamines [68].

It is now very well known, use of microwave irradiation in synthetic chemistry has become such a popular technique in the scientific community that in a few years, most chemists will probably use microwave energy to carry out chemical reactions on a laboratory scale [69]. In many of the reactions published in the literature, microwave heating has been shown to dramatically reduce reaction times, enhanced product purities by reducing unwanted side reactions compared to the conventional method of heating and increased product yields [70]. Several reviews have been published on the application of microwaves in organic synthesis, nanotechnology, homogeneous and heterogeneous catalyses, medicinal chemistry, polymer synthesis, material science, drug delivery [70]. We have synthesized nitriles earlier using catalysts like $\mathrm{ZnCl}_{2}$ [71], pyridine [72] and $p$-TsOH [73], but here we are making an attempt to use a reusable catalyst for the synthesis of nitriles. Thus incorporating all these green conditions we have developed a highly efficient and environmentally safe protocol for the synthesis of nitriles as shown in Scheme 1.

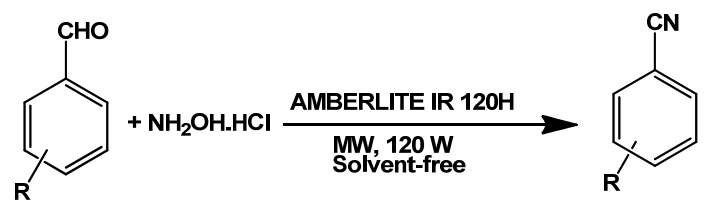

$\mathrm{R}=-\mathrm{H} ; 4-\mathrm{OCH}_{3} ; 3-\mathrm{OCH}_{3} ; 2-\mathrm{OH} ; 4-\mathrm{OH}$;

$3-\mathrm{OCH}_{3} ; 4-\mathrm{OH} ; 4-\mathrm{Cl} ; 4-\mathrm{NO}_{2} ; 4-\mathrm{N}\left(\mathrm{CH}_{3}\right)_{2}$.

Scheme 1

\section{Experimental}

\subsection{Material and instruments}

All the aldehydes, hydroxyl ammonium chloride, amberlite IR- $120 \mathrm{H}$ and analytical grade solvents are commercial products of Sd fine-chem., India make and used without further purification. The silica coated catalysts were obtained according to the methods reported in the literature [74-77]. All microwave reactions were conducted in a MILESTONE microwave reactor at $120 \mathrm{~W}$ for $2 \mathrm{~min}$. Progress of the reaction was monitored on thin layer chromatography (TLC). TLC was carried out on Merck made silica gel $60 \mathrm{~F}_{254}$ plates with ethylacetate:hexane (1:4) system. The formation of nitriles was confirmed by recording the IR spectra on Bruker Alpha-T ATR/FTIR spectrometer. Yields refer to isolated yields of the products.

\subsection{General procedure for the preparation of nitriles}

Aldehyde (2 mmol), hydroxyl ammonium chloride (2 mmol) and amberlite IR $120 \mathrm{H}(0.1 \mathrm{~g})$ were taken in pyrex tube and subjected to microwave irradiation at $120 \mathrm{~W}$ in a microwave reactor. The progress of the reaction was checked at regular intervals using TLC and irradiation was continued for the required time as mentioned in Table 1 until no further progress in the reaction was observed. After which the reaction mixture was cooled, $5 \mathrm{~mL}$ of $\mathrm{CH}_{2} \mathrm{Cl}_{2}$ was added, catalyst was filtered and the resultant solution was washed with water, the organic layer was separated, dried over anhydrous $\mathrm{CaCl}_{2}$ and evaporated under reduced pressure to get crude product, which was purified by recrystallization or column chromatography using ethyl acetate/hexane as eluent to afford the desired nitrile in good yields.

\section{Results and discussion}

As already known the use of heterogeneous catalyst in organic synthesis are of immense benefit and since to the best of our knowledge not many reports exist in literature on the use of heterogeneous catalyst combined with microwaves for the synthesis of nitriles. Hence we aimed at employing heterogeneous catalyst for the conversion of aldehydes to nitriles, to do so various silica coated catalyst such as $\mathrm{SiO}_{2}-$ $\mathrm{HClO}_{4}$ [74], $\mathrm{PPA}-\mathrm{SiO}_{2}$ [75], silica chloride [76] and silica sulphuric acid [77] were prepared and used for the synthesis of nitriles using anisaldehyde as the model substrate, product formation was noticed but yield was not satisfactory, when Amberlite IR-120H was employed as catalyst under reflux, within $80 \mathrm{~min}$ the formation of product was observed in good yield, but when the same reaction was carried out under solvent-free microwave irradiation the yield further increased with considerable decrease in reaction time to just $2 \mathrm{~min}$.

A comparative study of the model reaction under conventional method and microwave heating is shown Table 2 .

To optimize the ideal heating conditions, the reaction of 2 mmole of anisaldehyde, 2 mmole of hydroxyl ammonium chloride and $0.25 \mathrm{~g}$ of Amberlite IR- $120 \mathrm{H}$ were taken and the mixture was subjected to microwave irradiation at 80,120 and $200 \mathrm{~W}$ for $2 \mathrm{~min}$, best result was obtained when the reaction was carried out at $120 \mathrm{~W}$. The reaction time was optimised by irradiating the mixture at $120 \mathrm{~W}$ for $5 \mathrm{~min}$, a sticky over heated mass was formed, which when extracted into an organic solvent, showed very little formation of product. Next, the reaction was irradiated and monitored at an interval of $20 \mathrm{sec}$ each by TLC, at every interval there was noticeable increase in the yield. Finally after 2 min maximum formation of 4-methoxybenzonitrile (85\%) was observed, further heating did not improve the yield.

Optimization of catalyst loading and its reusability was the next concern, to start with $0.25 \mathrm{~g}$ of Amberlite IR-120H was used, decrease of catalyst loading to $0.2 \mathrm{~g}$ did not alter the product yield, further reduction in the amount of catalyst to 0.1 $\mathrm{g}$ did not affect the yield of nitrile formed, but reduction to below $0.1 \mathrm{~g}$ led to decrease in the formation of nitrile.

The reusability of the catalyst was checked for four consecutive trials by washing the catalyst obtained from each trial with ethyl acetate several times and drying it in a preheated oven at $60^{\circ} \mathrm{C}$. It was noticed that the efficiency of the catalyst remained unaltered giving yields of the product as 88 , 85,83 and $80 \%$, respectively (Figure 1).

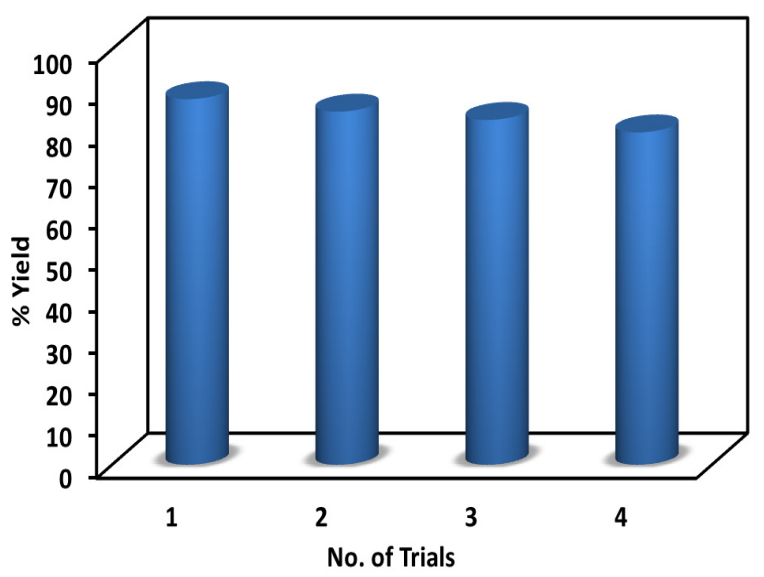

Figure 1. Reusability of Amberlite IR- $120 \mathrm{H}(0.1 \mathrm{~g})$ for the conversion of aldehydes to nitriles. 
Table 1. Synthesis of various substituted aromatic nitriles using a reusable catalyst.

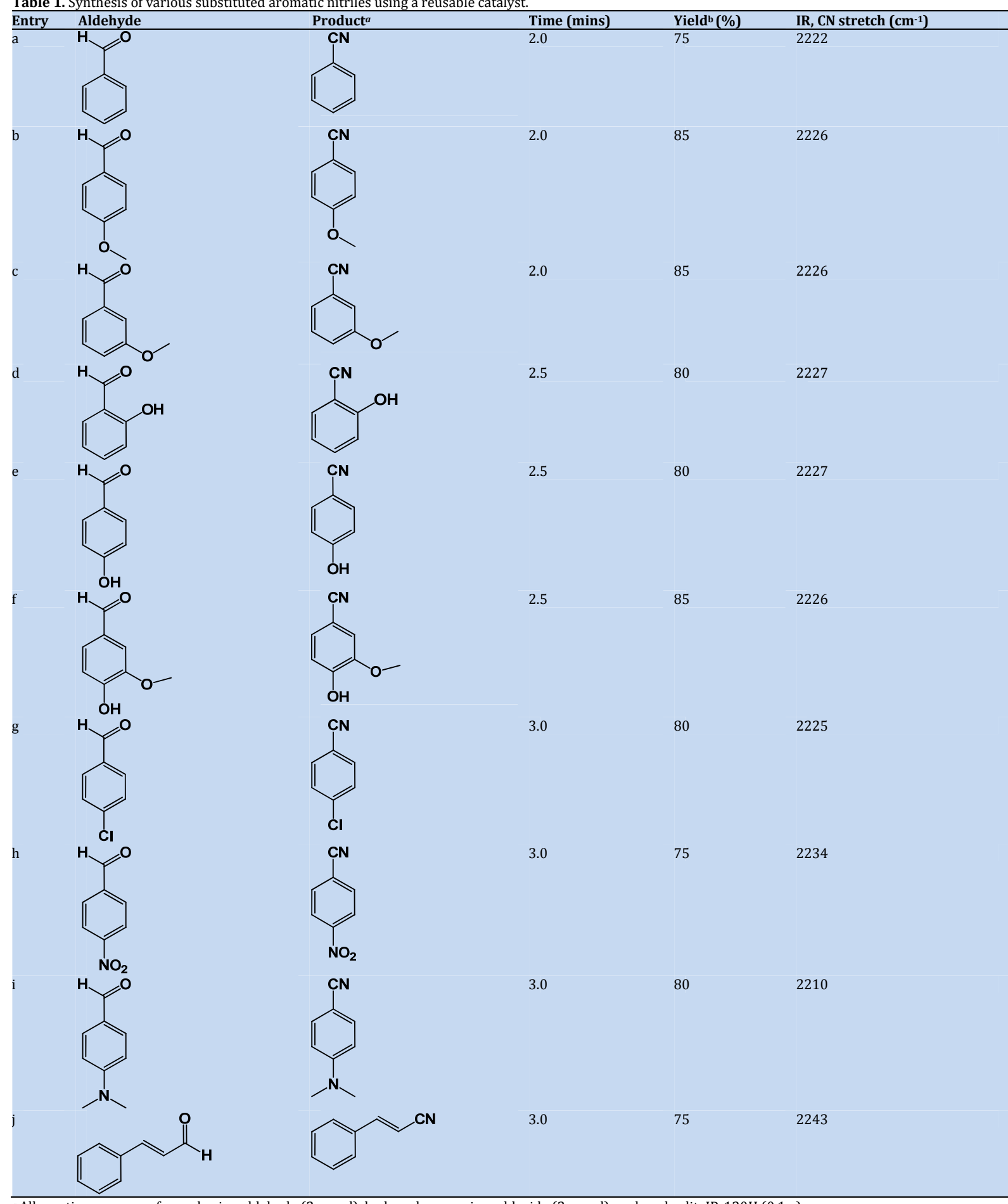

${ }^{a}$ All reactions were performed using aldehyde ( $\left.2 \mathrm{mmol}\right)$, hydroxyl ammonium chloride $(2 \mathrm{mmol})$, and amberlitelR-120H $(0.1 \mathrm{~g})$.

${ }^{b}$ Isolated yield; all the compounds are known, IR spectral data of all the products agree with the reported values.

Table 2. Comparative study of conversion of anisaldehyde (2 mmol) to 4-methoxy benzonitrile in the presence of amberlite IR-120H under various reaction conditions.

\begin{tabular}{llll}
\hline Entry & Reaction condition & Time (min) & Yield (\%) \\
\hline a & Silent & 60 & Nil \\
b & Reflux & 60 & 20 \\
c & Solvent free at $70{ }^{\circ} \mathrm{C}$ & 60 & 30 \\
d & Solvent free at $80{ }^{\circ} \mathrm{C}$ & 60 & 40 \\
e & Solvent free at $120{ }^{\circ} \mathrm{C}$ & 30 & 50 \\
f & Solvent free MW at $120 \mathrm{~W}$ & 2 & 85 \\
\hline
\end{tabular}



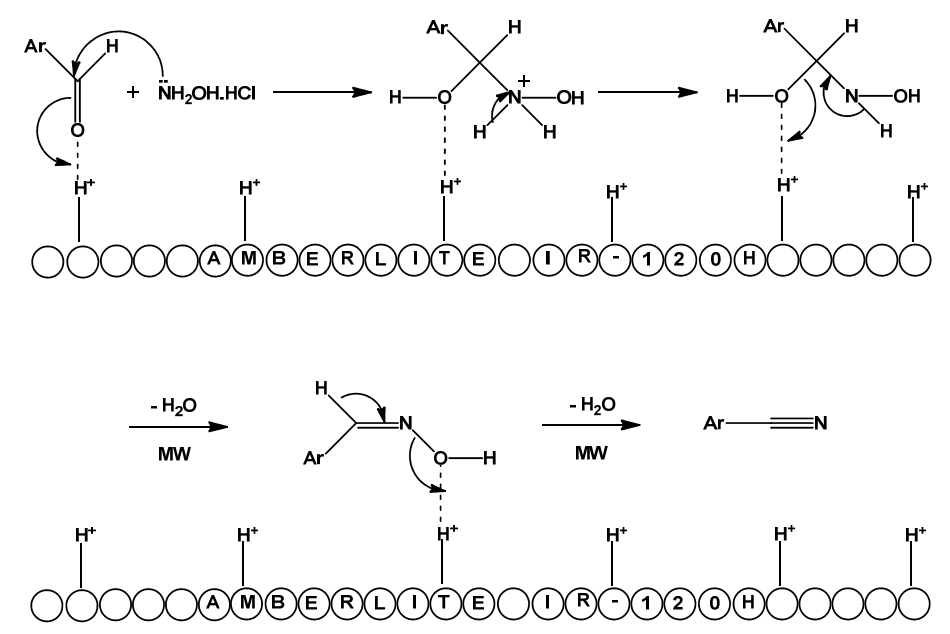

Scheme 2

At this point we wanted to assess the generality of this transformation and subjected a variety of araldehydes to the optimized reaction conditions. The results of these reactions are summarized in Table 1. From the Table 1, it is clear that reaction with araldehydes having electron donating and electron with-drawing groups on the arene nucleus proceed significantly well to afford the corresponding nitriles in good yield.

\subsection{Mechanism}

The formation of nitriles from aldehydes and hydroxyl ammonium chloride catalysed by Amberlite IR-120H proceeds via the nucleophillic attack of hydroxyl ammonium chloride on the carbonyl carbon of aldehyde co-ordinated to Amberlite IR$120 \mathrm{H}$ (as co-ordination of oxygen atom of the aldehyde to the acidic catalyst makes the carbon of the aldehyde more electrophillic and hence facilitates the nucleophillic attack to take place readily), this followed by rearrangement and loss of water gives the intermediate oxime, the oxime on dehydration provides the nitrile in good yield (The dehydration steps are aided by the high temperature generated in the microwave reactor) (Scheme 2).

\section{Conclusions}

We have successfully developed a rapid and efficient method for synthesizing a variety of nitriles directly from aldehydes employing readily available inexpensive catalyst using environmentally safe conditions. We feel that the methodology developed is a valuable addition to the existing methods as it makes use of a reusable catalyst for affording the nitriles in good yields in a short duration of time, thereby making the process green.

\section{Acknowledgements}

Authors are thankful to Centre for Research, Christ University, Bangalore for providing laboratory facilities and grants. We thank Dr. Yajnavalkya Subbaray Bhat, Professor and Head, Department of Chemistry and Prof. Bangalore Sheenappa Jaiprakash, Professor, Department of Chemistry, Bangalore Institute of Technology, Bengaluru, India, for providing the MILESTONE Microwave Reactor facility, and Mr. Ramesh, Research Scholar, Bangalore Institute of Technology, Bengaluru, India, for the timely help.

\section{References}

[1]. Manish, S. K.; Mahesh L. K. J. Org. Chem. 2009, 74, 3079-3084

[2]. Tennant, G.; Barton, D.; Ollis, D. W.; Sutherland, I. O. Comprehensive Organic Chemistry Eds, $2^{\text {nd }}$ edition, Pergamon Press. Oxford, 1979.

[3]. Srinivas, K. V. N. S. Bolla Reddy, E. Biswanath, D. Synlett. 2002, 4 625-627.

[4]. Lai, G.; Bhamare, N. K.; Anderson, W. K. Synlett. 2001, 2, 230-231.

[5]. Janakiraman, M. N.; Watenpaugh, K. D.; Tomich, P. K.; Chong, K. -T.; Turner, S. R.; Tommasi, R. A.; Thaisrivongs, S. Strohbach, J. W. Bioorg. Med. Chem. Lett. 1998, 8, 1237-1242.

[6]. Kamal, A.; Arifuddin, M.; Rao, V. Synth. Commun. 1998, 28, $4507-$ 4512.

[7]. Wittenberger, S. J.; Donner, B. G. J. Org. Chem. 1993, 58, 4139-4141.

[8]. Bailey, T. R.; Diana, G. D.; Kowalczyk, P. J.; Akullian, V.; Eissenstat, M A.; Cutcliffe, D.; Mallamo, J. P.; Carabateas, P. M.; Pevear, D. C. J. Med. Chem. 1992, 35, 4628-4633.

[9]. Kadaba, P. K. Synthesis 1973, 71-84

[10]. Gu, X. -H.; Wan, X. -Z.; Jiang, B. Bioorg. Med. Chem. Lett. 1999, 9, 569572.

[11]. Chihiro, M.; Nagamoto, H.; Tekemura, I.; Kitano, K.; Komatsu, H.; Sekiguchi, K.; Tabusa, F.; Mori, T.; Tominaga, M. Yabuuchi, Y. J. Med. Chem. 1995, 38, 353-558.

[12]. Moody, C. J.; Doyle, K. J. Prog. Heterocyclic Chem. 1997, 9, 1-16.

[13]. Ducept, P. C.; Marsden, S. P. Synlett 2000, 692-694.

[14]. Jnaneshwara, G. K.; Deshpande, V. H.; Lalithambika, M. Ravindranathan, T.; Bedekar, A. V. Tetrahedron Lett. 1998, 39, 459462.

[15]. Fabiani, M. E. Drug News Perspect 1999, 12, 207-215.

[16]. North, M.; Katritzky, A. R.; Meth-Cohn, O.; Rees, C. W.; Pattenden, G. Comprehensive Organic Functional Group Transformations, $3^{\text {rd }}$ edition, Pergamon :Oxford, 1995.

[17]. Friedrich, K.; Wallenfels, K. The chemistry of the cyano group. Wiley-InterScience Publishers New York, 1970.

[18]. Miller, S. J.; Manson, J. L. Acc. Chem. Res. 2001, 34, 563-570.

[19]. Larock, R. C. Comprehensive Organic Transformations, $2^{\text {nd }}$ edition, Wiley New York, 1999.

[20]. Sharghi, H.; Sarvari, M. H. Synthesis 2003, 243-246.

[21]. Lingaiah, N.; Narender, R. Synth. Commun. 2002, 32, 2391-2394.

[22]. Yang, S. A.; Chang, S. Org. Lett. 2001, 3, 4209-4211.

[23]. Ghiaci, M.; Bakhtiari, K. Synth. Commun. 2001, 31, 1803-1807.

[24]. Desai, D. G.; Swami, S. S.; Mahale, G. D. Synth. Commun. 2000, 30 1623-1625.

[25]. Jose, B.; Sulatha, M. S.; Pillai, P. M.; Prathapan S. Synth. Commun 2000, 30, 1509-1514.

[26]. Chaudhari, S. S.; Akamanchi, K. G. Synth. Commun. 1999, 29, 1741 1745.

[27]. Wang, E. C.; Lin, G. J. Tetrahedron Lett. 1998, 39, 4047-4050.

[28]. Fukuzawa, S. -I.; Yamaishi, Y.; Furuya, H.; Terao, K.; Iwasaki, F. Tetrahedron Lett. 1997, 38, 7203-7206.

[29]. Cho, B. R.; Jang, W. J.; Je, J. T.; Bartsch, R. A. J. Org. Chem. 1993, 58, 3901-3904.

[30]. Hendrickson, B. J.; Hussoin M. S. J. Org. Chem. 1987, 52, 4137-4139.

[31]. Kim, S.; Yi, K. Y. Tetrahedron Lett. 1986, 27, 1925-1928.

[32]. Arrieta, A.; Aizpurua, J. M.; Palomo, C. Tetrahedron Lett. 1984, 25, 3365-3368.

[33]. Jung, M. E.; Long-Mei, Z. Tetrahedron Lett. 1983, 24, 4533-4534. 
[34]. Konwar, D.; Boruah, R. C.; Sandhu, J. S. Tetrahedon Lett. 1990, 34, 1063-1064.

[35]. Larock, L. C. Comprehensive Organic Transformation A guide to functional group preparation. VCH Inc: New York, 989.

[36]. Bose, S.; Jayalakshmi, B.; Goud, P. R. Synthesis 1999, 10, 1724-1726

[37]. Kato, Y.; Ooi, R.; Asano, Y. J. Mol. Cat. B: Enzym. 1999, 6, 249-256.

[38]. Hegarty, A. F.; Tuohey, P. J. J. Chem. Soc., Perkin Trans. 2 1980, 9, 1313-1317.

[39]. Telvekar, V. N.; Patel, K. N.; Kundiakar, H. S.; Chaudhari, H. K. Tetrahedron Lett. 2008, 49, 2213-2215.

[40]. Gucma, M.; Golebiewski, W. M. Synthesis 2008, 1997-1999.

[41]. Yamaguchi, K.; Fujiwara, H.; Ogasawara, Y.; Kotani, M.; Mizuno, N. Angew Chem, Int Ed. 2007, 46, 3922-3925.

[42]. Supsana, P.; Liaskopoulos, T.; Tsoungas, P. G.; Varvounis, G. Synlett 2007, 2671- 2674

[43]. Zhu, J. L.; Lee, F. Y.; Wu, J. D.; Kuo, C. W.; Shia, K. S. Synlett 2007, 1317-1319.

[44]. Iranpoor, N.; Firouzabadi, H.; Jamalian, A.; Tamami, M. Org. Chem. Lett. 2006, 3, 267- 270.

[45]. Sarvari, M. H. Synthesis 2005, 787-790.

[46]. Li, D.; Shi, F.; Guo, S.; Deng, Y. Tetrahedron Lett. 2005, 46, 671-674.

[47]. Yan, P.; Batamack, P.; Prakash, G. K. S.; Olah, G. A. Cat. Lett. 2005, 101, 141-143.

[48]. Coskun, N.; Synth Commun. 2004, 34, 1625-1630.

[49]. Kiasat, A. R.; Kazemi, F.; Khosravian, F. Phosphorus Sulfur Silicon Relat. Elem. 2003, 178, 1377-1383.

[50]. Telvekar, V. N.; Akamanchi, K. G. Synth. Commun. 2004, 34, 23312336.

[51]. Olah, G. A.; Narang, S. C.; Salem, G. F. Synthesis 1980, 659-659.

[52]. Denis, J. N.; Krief, A. J. Chem. Soc., Chem. Commun. 1980, 544-545.

[53]. Olah, G. A.; Vankar, Y. D.; Garcia-Luna, A. Synthesis 1979, 227-228.

[54]. Carotti, A.; Campagna, F.; Ballini, R. Synthesis 1979, 56-58.

[55]. Dulcere, J. P. Tetrahedron Lett. 1981, 22, 1599-1600.

[56]. Cooper, D.; Trippett, S. Tetrahedron Lett. 1979, 19, 1725-1726.

[57]. Vowinkel, E.; Bartel, J. Chem. Ber. 1974, 107, 1221-1227.

[58]. Sosnovsky, G.; Krogh, J. A. Synthesis 1978, 703-705.

[59]. Ho, T. L.; Wong, C. M. Synth. Commun. 1975, 5, 423-425.

[60]. Shimada, J.; Ushigome, A.; Itabashi, K. YukiGosei Kagaku Kyokaishi 1977, 35, 913-913.

[61]. Chao-Jun Li, Barry , M. Trost Proc. Natl. Acad. Sci. U S A. 2008, 105, 13197-13202.

[62]. Sharghi, H.; Sarvari, M. H. Tetrahedron 2002, 58, 10323-10328.

[63]. Loupy, A.; Perreux, L.; Liagre, M.; Burle, K.; Moneuse, M. Pure Appl. Chem. 2001, 73, 161-166.

[64]. Madhusudana Reddy, M. B.; Aatika, N.; Pasha, M. A. Chinese J. Catal. 2010, 31, 518-520.

[65]. Vinod, K. T.; Neetu, T.; Diksha, K.; Rama, P. T. Monatsh. Chem. 2007, $138,1297-1302$

[66]. Mehdi, F.; Hassan, G. Arabian J. Chem. 2011, article in press.

[67]. Pasha, M. A.; Aatika N. J. Saudi Chem. Soc. 2011, article in press.

[68]. Neetu, T.; Diksha, K.; Vinod, K. T.; Rama, P. T. Tetrahedron Lett. 2003, 44, 6639-6642.

[69]. Krstenansky, J. L.; Cotterill, I. Curr. Opin. Drug. Di. De. 2000, 4, 454461.

[70]. Adnadjevic, B.; Jovanovic, J. The Effect of Microwave Heating on the Isothermal Kinetics of Chemicals Reaction and Physicochemical Processes, In Advances in Induction and Microwave Heating of Mineral and Organic Materials, ed. Stanislaw Grundas, INTECHWEB.ORG, 2011, 391-422.

[71]. Pasha, M. A.; Aatika, N. Synth. Commun. 2010, 40, 1276-1279.

[72]. Pasha, M. A.; Aatika, N. Indian J. Chem. 2010, 49B, 1127-1129.

[73]. Madhusudana Reddy, M. B.; Pasha, M. A. Synth. Commun. 2010, 40, 3384-3389.

[74]. Srihari, G.; Nagaraju, M.; Murthy, M. M. Helv. Chim. Acta 2007, 90, 1497-1504.

[75]. Shaterian, H. R.; Ghashang, A. H. M. Synth. Commun. 2008, 38, 33753389.

[76]. Karade, H.; Sathe, M.; Kaushik, M. P. Catal. Commun. 2007, 8, 741746.

[77]. Mirjalili, B. F.; Zolfigol, M. A.; Bamoniri, A. Molecules 2002, 7, 751755. 